\title{
No Reproductive Interference from an Alien to a Native Species in Cerastium (Caryophyllaceae) at the Stage of Seed Production
}

\author{
Koh-Ichi Takakura \\ Division of Urban Environment, Osaka City Institute of Public Health and Environmental Sciences, 8-34 Tojo-cho, \\ Tennoji, Osaka 543-0026, Japan \\ Correspondence should be addressed to Koh-Ichi Takakura, takakura@nature.email.ne.jp
}

Received 28 November 2012; Accepted 20 December 2012

Academic Editors: F. A. Culianez-Macia and T. L. Weir

Copyright (๑) 2012 Koh-Ichi Takakura. This is an open access article distributed under the Creative Commons Attribution License, which permits unrestricted use, distribution, and reproduction in any medium, provided the original work is properly cited.

\begin{abstract}
Reproductive interference, adverse interspecific interaction during the mating process, has been regarded as a powerful driver of species displacement between species. Recent empirical reports have described its importance in biological invasions. This study was undertaken to test whether a rare herbaceous plant species indigenous to Japan suffered reproductive interference from an alien species of the genus Cerastium. Field observations and a transplanting experiment were conducted to ascertain the effects of coexistence with an alien species on the seed production of the native species. Results show that coexistence with the alien species did not significantly decrease seed numbers, but it significantly affected the seed weight only in field observations. In this study, the reproductive process of the native species was examined only at or before the seed production stage. Because the interspecific pollen transfer might produce hybrids with low viability or fertility, reproductive interference cannot be denied in this study. To test reproductive interference at such latter stages, additional studies should be conducted. Consequently, detection of reproductive interference demands high costs in some species. Based on these results and suggestions, the necessity of narrowing down the target species for testing of reproductive interference is discussed to elucidate the universality of reproductive interference.
\end{abstract}

\section{Introduction}

In recent years, reproductive interference has gathered much attention as a powerful force driving displacement between species. Reproductive interference refers to any interspecific interaction during the mating process that decreases the reproductive success of either or both interacting species [1]. Typical interactions causing reproductive interference are interspecific courtship in animals and interspecific pollen transfer in plants. Reproductive interference can easily eliminate species of smaller abundance or ones with high sensitivity to reproductive interference $[2,3]$ because of its frequency dependence [3]. Consequently, reproductive interference has become an important key to determining the community structure of both animals and plants $[4,5]$.

Reproductive interference has been regarded as important also in terms of conservation biology. Recent studies have demonstrated that it is involved with displacement of the native by the alien species. For example, the native dandelion in Japan has been displaced by the alien congener, especially in urban areas. Our previous reports have described that the reproductive interference played a crucial role in displacement $[6,7]$. Similarly, reproductive interference has been suspected as an important factor of the extinction of the Japanese cocklebur, Xanthium japonica, in western Japan [8]. More examples of reproductive interference have been reported in animals [9-11]. Consequently, reproductive interference has often been found in the pair of the alien species and its allied native species and has been recognized as an important factor related to the invasiveness of alien species.

It is a fact that considerable reproductive interference has been detected in pairs of alien species and allied native species, but is this truly universal? To assess the true universality of the phenomenon, it is necessary to consider publication bias [12], which occurs because researchers 
might not seek to report negative results and editors might not desire to accept such reports for publication. In fact, most published studies of reproductive interference have reported positive results only $([6,7,13]$, but see [14]). To discuss the universality of the reproductive interference fairly, it is necessary to review not only the detection of the reproductive interference but also reports of its absence. Furthermore, the pattern of the significant reproductive interference should be discussed to reveal what factors and conditions are involved with the intensity and direction of the reproductive interference.

This study tested the reproductive interference between the native and the alien species pair of mouse-ear chickweeds of the genus Cerastium. The native species was the Japanese mouse-ear chickweed, which is rare to the present day. However, the alien species, sticky mouse-ear chickweed, is abundant throughout the world, including Japan. The reproductive interference that the native species suffered from the alien species was tested using field observations and a transplanting experiment. Based on these results, the universality of reproductive interference in plants and how it should be addressed are discussed.

\section{Materials and Methods}

2.1. Study Species. The Japanese mouse-ear chickweed, Cerastium holosteoides Fries var. hallaisanense (Nakai) Mizushima, a herbaceous biennial plant endemic in Japan [15] (Figure 1), was a common weed a century ago [16], but it is a rare species in residential and commercial areas in the present day [17]. Its present habitats are limited to roadsides and orchards in mountainous regions [17]. It cannot be observed in lowland regions of western Japan today (Takakura KI personal obs.).

However, the alien congeneric species is the sticky mouse-ear chickweed, C. glomeratum Thuill (Figure 1). This species was reported to establish not only in Japan but also in many other countries [18]: it is a cosmopolitan alien weed and is quite common also in Japan [17]. This species appeared to displace $C . h$. hallaosanense in developed areas of Japan [17], but the direct adverse effect on the growth and reproduction of the native species has not been studied. The pollinator fauna on these two species remains unknown, but these two plant species probably share pollinators because their flower morphologies are simple and mutually similar (Figure 1). Moreover, the flowering seasons are early spring in both species [15].

2.2. Field Observation. In these observations, the $C . h$. var. hallaisanense seed production of individuals coexisting with the alien $C$. glomeratum and those without the alien species in close vicinity were compared to test the effects of the alien species on the seed production in the native species. This study site was a rice field on the periphery of KawachiNagano, Osaka, Japan $\left(34^{\circ} 23^{\prime} 32^{\prime \prime} \mathrm{N}, 135^{\circ} 34^{\prime} 37^{\prime \prime} \mathrm{E}\right)$ on 20 April 2007. The area containing the site was an agricultural landscape surrounded by mountains. I collected fruits that

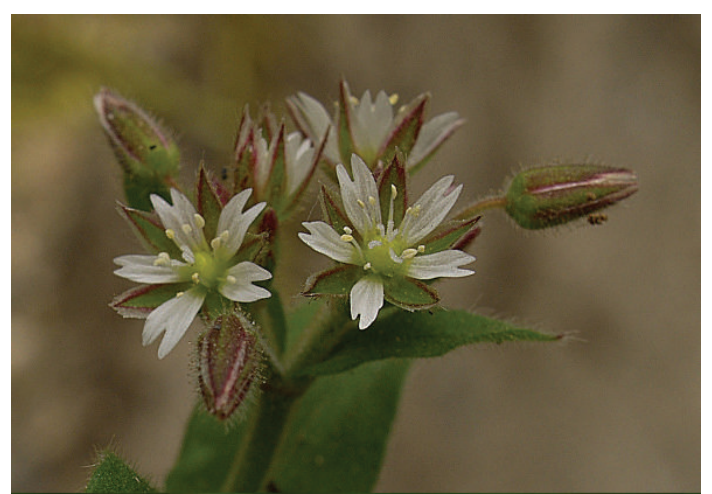

(a)

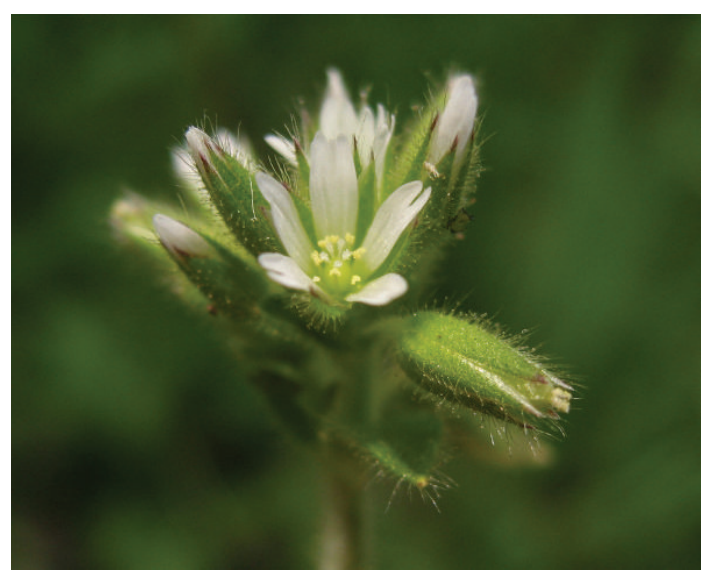

(b)

FIGURE 1: Flowers of the native species, C. $h$. var. hallaisanense (a), and the alien species, C. glomeratum (b).

had grown sufficiently to count seeds in them and immediately before dehiscence from $22 C$. $h$. var. hallaisanense individuals. Ten individuals grew within a $30 \mathrm{~cm}$ radius from the closest individuals of C. glomeratum (coexisting group). The remaining 12 individuals occurred $1 \mathrm{~m}$ or farther apart from the closest individuals of C. glomeratum (control).

Collected fruits were dissected in the laboratory to count their seeds. Furthermore, after drying for two weeks at room temperature, the seed weight was measured in a mass for every fruit with an electric balance (Mettler Toledo AG 285; Mettler Instrumente AG, Zurich, Switzerland) with $0.1 \mathrm{mg}$ accuracy.

2.3. Transplanting Experiment. Plants were reared in pots and used for this experiment. Seeds of $C . h$. var. hallaisanense were collected at the site of Kawachi-Nagano (see above) during May 2006. Seeds were put individually on soil in plastic pots (75 mm diameter, $75 \mathrm{~mm}$ depth) in July 2006. Pots were put in the laboratory yard of the Osaka City Institute of Public Health and Environmental Sciences, Osaka, Japan $\left(34^{\circ} 39^{\prime} 47^{\prime \prime} \mathrm{N}, 135^{\circ} 31^{\prime} 42^{\prime \prime} \mathrm{E}\right)$ and were irrigated arbitrarily. Individuals that had flowered in April 2007 were used for the experiment. 


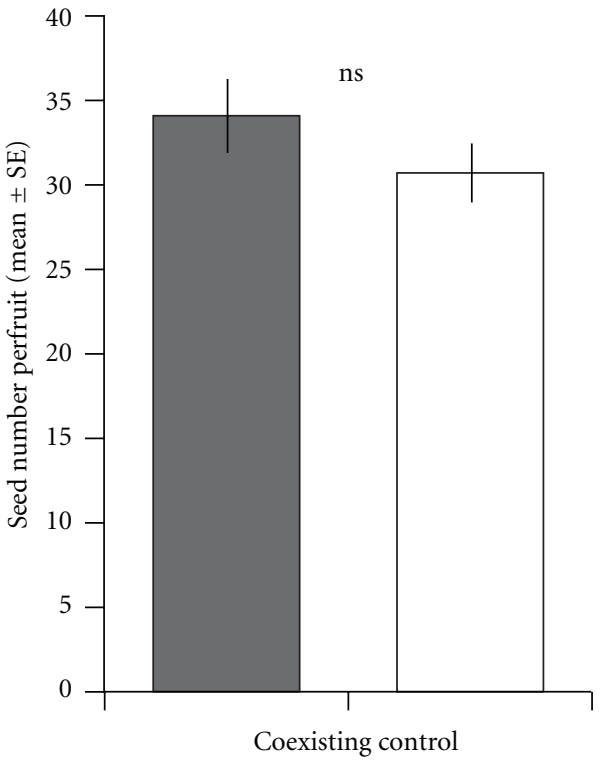

(a)

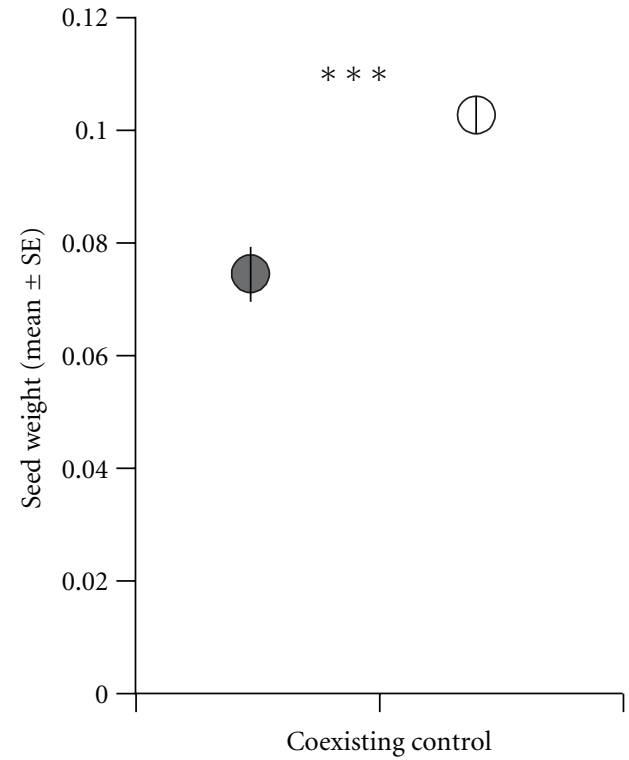

(b)

FIGURE 2: Seed numbers per fruit (a) and seed weights (b) in fruits produced from C. $h$. var. hallaisanense individuals that coexisted with the alien individuals (filled bar) and those of the control (open bar). Error bars represent $95 \%$ confidence interval. Symbols denote statistical significance (GLMMs; $* * *, P<0.001 ; \mathrm{ns}, P>0.05)$.

The experimental site was Tsurumi Park, Osaka, Japan $\left(34^{\circ} 42^{\prime} 32^{\prime \prime} \mathrm{N}, 135^{\circ} 34^{\prime} 55^{\prime \prime} \mathrm{E}\right)$. Eighteen pots, each with an individual of $C . h$. var. hallaisanense, were put in the vicinity of different patches of C. glomeratum in the site on 16 April 2007. These were designated as the coexisting group below as above. The 18 different individuals (pots) were left in the laboratory yard (control). Before the experiment, all flowers and fruits were removed with precision scissors for all individuals to prevent seeds that had been produced before the experiment from being counted afterward. Ten days after transplanting, all pots were brought to the laboratory yard again and were irrigated arbitrarily. Fruits borne during the transplantation were cropped immediately before dehiscence. Their number and weight were measured as the observation described above.

2.4. Statistical Analyses. Data from the observations and the experiment were similarly analyzed statistically. The seed numbers were compared between treatments: the coexisting groups and controls. Generalized linear mixed models (GLMMs, [19]) were applied for all datasets. In GLMMs for seed numbers, Poisson distributions were assumed as error structures. The response was the number of seeds in each fruit and the factor was each treatment: coexisting with the alien species or not. The individual of $C$. $h$. var. hallaisanense was treated as a random effect that would absorb the interindividual variance. For the seed weight, first, the weight per seed was calculated for each fruit. Subsequently, it was compared between groups. In these analyses, the Gaussian distributions were assumed as error structures. The factor and the random effect was the same as in analyses of seed numbers. All analyses were conducted using R 2.15.1 [20].

\section{Results}

3.1. Field Observation. The seed number per fruit was $34.10 \pm 2.19$ (mean \pm SE) in the mixed group and $30.7 \pm$ 1.75 in the control of $C . h$. var. hallaisanense (Figure 2(a)). The difference between groups was not significant (GLMM, coefficient of the coexisting group $\pm \mathrm{SE}=0.222 \pm 0.184, Z=$ $1.21, P=0.227)$. The seed weight was $0.075 \pm 0.005 \mathrm{mg}$ in the coexisting group and smaller than that in the control, $0.103 \pm$ $0.003 \mathrm{mg}$ (Figure 2(b)). The difference between groups was significant (GLMM, coefficient of the coexisting group \pm $\mathrm{SE}=-0.029 \pm 0.006, t=4.52, P<0.001)$.

3.2. Transplanting Experiment. The seed number per fruit was $34.8 \pm 1.78$ (mean $\pm \mathrm{SE}$ ) in the mixed group and $30.9 \pm$ 1.71 in the control of $C . h$. var. hallaisanense (Figure 3(a)). The difference between groups was not significant (GLMM, coefficient of mixed group $\pm \mathrm{SE}=-0.102 \pm 0.126, Z=$ $-0.82, P=0.415)$. The seed weight was $0.100 \pm 0.004$ in the mixed group and $0.106 \pm 0.006$ in the control (Figure 3(b)). The difference between groups was not significant (GLMM, coefficient of mixed group $\pm \mathrm{SE}=-0.005 \pm 0.012, t=0.375$, $P=0.710)$.

\section{Discussion}

In this study, both the field observations and the transplanting experiment demonstrated that coexistence with the alien congener did not decrease seed production of the native species, $C$. $h$. var. hallaisanense, which appeared to have out-competed the alien species. The seed weight was significantly lower in field observations but the difference 


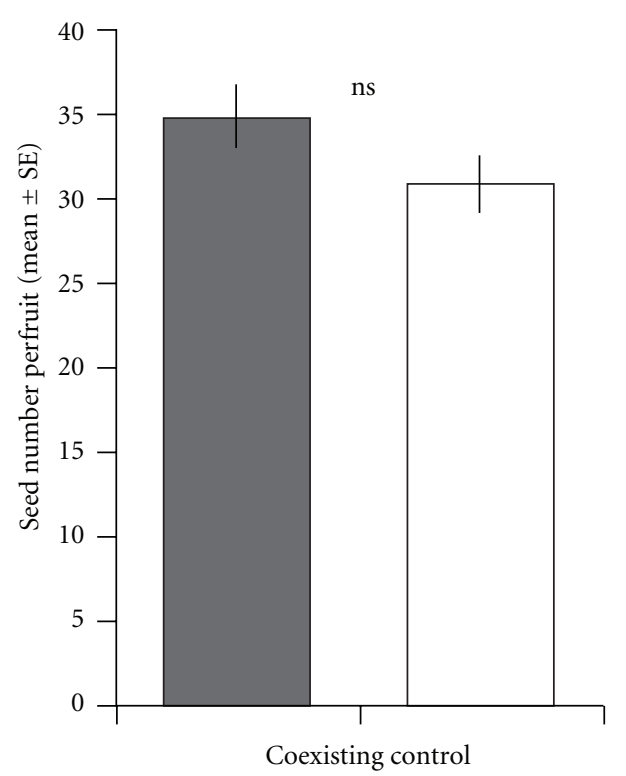

(a)

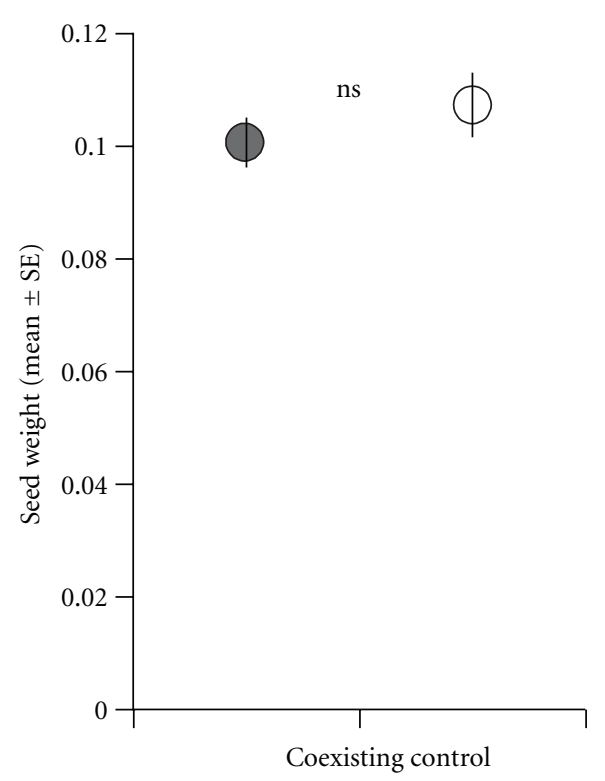

(b)

FIGURE 3: Seed numbers per fruit (a) and seed weights (b) in fruits produced from C. $h$. var. hallaisanense individuals that transplanted in the vicinity of the patches of the alien individuals (filled bar) and those of the control (open bar). Error bars represent a 95\% confidence interval. Symbols denote statistical significance (GLMMs; ns, $P>0.05$ ).

was not significant in the transplanting experiment. These results demonstrate that the native species rarely suffered from competition with the congeneric alien species at or before the seed production stage.

Defects of the reproductive interference in plants can be expressed in various stages through reproductive processes, not only at or before the seed production, but also thereafter. Among studies of plants, reproductive interference has been detected predominantly at or before the seed production stage $[6,8,13]$. However, this predominance might be a publication bias because such a form of reproductive interference is easily detected and is therefore a positive result that is easily obtained. Some reproductive interference is expressed in subsequent developmental stages, although the possibility has not been discussed to date. Indeed, many past reports have described sterile hybrids between allied species pairs [21-23]. The production of sterile hybrids must directly engender the reproductive interference because such hybrids are produced at the sacrifice of fertile offspring. This study detected no definite reproductive interference at or before the seed production stage in $C . h$. var. hallaisanense. However, this failure does not necessarily indicate the absence of the reproductive interference from C. glomeratum to $C$. $h$. var. hallaisanense. For example, the lesser weight of seeds produced by $C$. $h$. var. hallaisanense thatcoexisted with C. glomeratum in the field might mean less viability of seedlings although it should be tested in future studies. For complete testing for the reproductive interference, the seed and seedling viability and fertility after growth should be examined.

Reproductive interference has gathered much attention as a novel hypothetical power driving the extinction of native species. In fact, recent studies have detected intense reproductive interference in some alien species $[6,8,10]$. However, complete testing of reproductive interference sometimes entails high costs for experiments because the reproductive interference can occur in several stages of reproduction: pollen transfer, attachment of pollen to the stigma, pollen tube growth, seed development, seedling viability, and offspring fertility. For efficient testing of the universality of reproductive interference in plants, we must narrow down target species by reference to past studies. Theoretical studies have predicted that the species pair could not coexist if there were reproductive interference between them $[3,24]$. Empirical studies have confirmed $[6,8-11$, 13], also suggested that reproductive interference tends to occur between congeneric species pairs. Based on these results, we should specifically examine congeneric species pairs without sympatric coexistence. The empirical testing of the reproductive interference in plants is just beginning. It is necessary to continue exploration of the universality and the importance of reproductive interference efficiently in plant community structures.

\section{Conclusion}

This study investigated a case in which no significant reproductive interference was detected, even in the species pair of the native and alien species between which displacement was suspected. However, the possibilities of reproductive interference expressed in stages of germination, seedling, and reproduction stages were not denied by results of this study. Additional studies must be undertaken to assess such 
possibilities. Furthermore, we must narrow down the target systems by reference to past theoretical and empirical studies.

\section{Acknowledgment}

This work was partly supported by a Grant-in-Aid for Young Scientists (B, no. 22710240) from the Ministry of Education, Culture, Sports, Science and Technology, Japan.

\section{References}

[1] J. Gröning and A. Hochkirch, "Reproductive interference between animal species," The Quarterly Review of Biology, vol. 83, no. 3, pp. 257-282, 2008.

[2] J. M. C. Ribeiro and A. Spielman, "The Satyr Effect: a model predicting parapatry and species extinction," The American Naturalist, vol. 128, no. 4, pp. 513-528, 1986.

[3] E. Kuno, "Competitive exclusion through reproductive interference," Researches on Population Ecology, vol. 34, no. 2, pp. 275-284, 1992.

[4] A. Hochkirch, J. Gröning, and A. Bücker, "Sympatry with the devil: reproductive interference could hamper species coexistence," Journal of Animal Ecology, vol. 76, no. 4, pp. 633642, 2007.

[5] D. A. R. Eaton, C. B. Fenster, J. Hereford, S. Q. Huang, and R. H. Ree, "Floral diversity and community structure in Pedicularis (Orobanchaceae)," Ecology, vol. 93, no. 8, supplement, pp. S182-S194, 2012.

[6] K. I. Takakura, T. Nishida, T. Matsumoto, and S. Nishida, "Alien dandelion reduces the seed-set of a native congener through frequency-dependent and one-sided effects," Biological Invasions, vol. 11, no. 4, pp. 973-981, 2009.

[7] T. Matsumoto, K. I. Takakura, and T. Nishida, "Alien pollen grains interfere with the reproductive success of native congener," Biological Invasions, vol. 12, no. 6, pp. 1617-1626, 2010.

[8] K. I. Takakura and S. Fujii, "Reproductive interference and salinity tolerance differentiate habitat use between two alien cockleburs: Xanthium occidentale and X. italicum (Compositae)," Plant Ecology, vol. 206, no. 2, pp. 309-319, 2009.

[9] E. A. Dame and K. Petren, "Behavioural mechanisms of invasion and displacement in Pacific island geckos (Hemidactylus)," Animal Behaviour, vol. 71, no. 5, pp. 1165-1173, 2006.

[10] A. D’Amore, E. Kirby, and V. Hemingway, "Reproductive interference by an invasive species: an evolutionary trap?" Herpetological Conservation and Biology, vol. 124, no. 4, pp. 325330, 2009.

[11] D. W. Crowder, M. I. Sitvarin, and Y. Carrière, "Plasticity in mating behaviour drives asymmetric reproductive interference in whiteflies," Animal Behaviour, vol. 79, no. 3, pp. 579$587,2010$.

[12] R. Rosenthal, "The "file-drawer problem" and tolerance for null results," Psychological Bulletin, vol. 86, no. 3, pp. 85-97, 1979.

[13] R. B. Runquist and M. L. Stanton, "Asymmetric and frequency-dependent pollinator-mediated interactions may influence competitive displacement in two vernal pool plants," Ecology Letters. In press.

[14] S. Nishida, K. I. Takakura, T. Nishida, T. Matsumoto, and M. M. Kanaoka, "Differential effects of reproductive interference by an alien congener on native Taraxacum species," Biological Invasions, vol. 14, no. 2, pp. 439-447, 2012.

[15] M. Kitagawa, "Caryophyllaceae," in Wildflowers of Japan, Y. Satake, T. Ooi, S. Kitamura, T. Watari, and T. Tominari, Eds., pp. 39-45, Heibonsha, Tokyo, Japan, 1982.

[16] T. Makino, Researches on Wild Plants, Sanbunsha, Tokyo, Japan, 1907.

[17] H. Fukuhara, R. Murata, H. Noda, and H. Igarashi, "Comparative ecology of the alien species, Cerastium glomeratum and native species, C. holosteoides var. hallaisanense: (1) distribution and life history," Memoirs of the Faculty of Education. Natural Sciences, vol. 10, no. 1, pp. 23-37, 2007 (Japanese).

[18] USDA, ARS, National Genetic Resources Program, "Cerastium glomeratum Thuill," in Germplasm Resources Information Network [Online Database], Beltsville, Md, USA, 2012.

[19] B. M. Bolker, M. E. Brooks, C. J. Clark et al., "Generalized linear mixed models: a practical guide for ecology and evolution," Trends in Ecology and Evolution, vol. 24, no. 3, pp. 127-135, 2009.

[20] R Core Team, R: A Language and Environment for Statistical Computing, R Foundation for Statistical Computing, Vienna, Austria, 2012.

[21] M. Ownbey, "Natural hybridization and amphiploidy in the genus Tragopogon," American Journal of Botany, vol. 37, no. 5, pp. 487-499, 1950.

[22] P. J. Brownsey, "Asplenium hybrids in the New Zealand flora," New Zealand Journal of Botany, vol. 15, no. 3, pp. 601-637, 1977.

[23] A. Aparicio, "Fitness components of the hybrid Phlomis x margaritae aparicio and silvestre (Lamiaceae)," Botanical Journal of the Linnean Society, vol. 124, no. 4, pp. 331-343, 1997.

[24] J. Yoshimura and C. W. Clark, "Population dynamics of sexual and resource competition," Theoretical Population Biology, vol. 45, no. 2, pp. 121-131, 1994. 

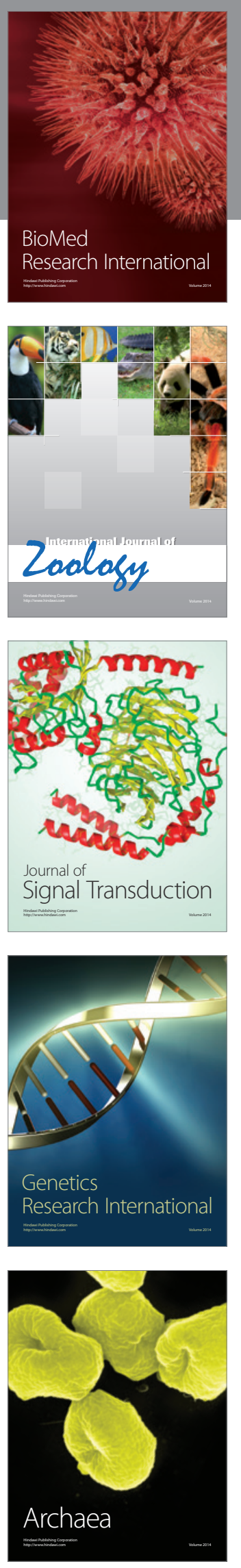
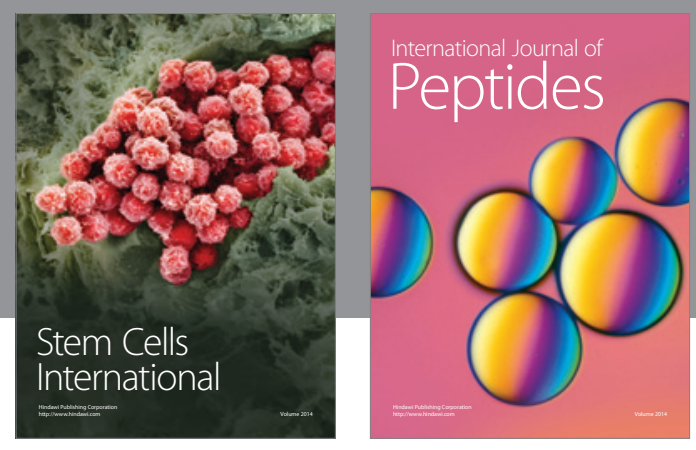

Submit your manuscripts at

http://www.hindawi.com
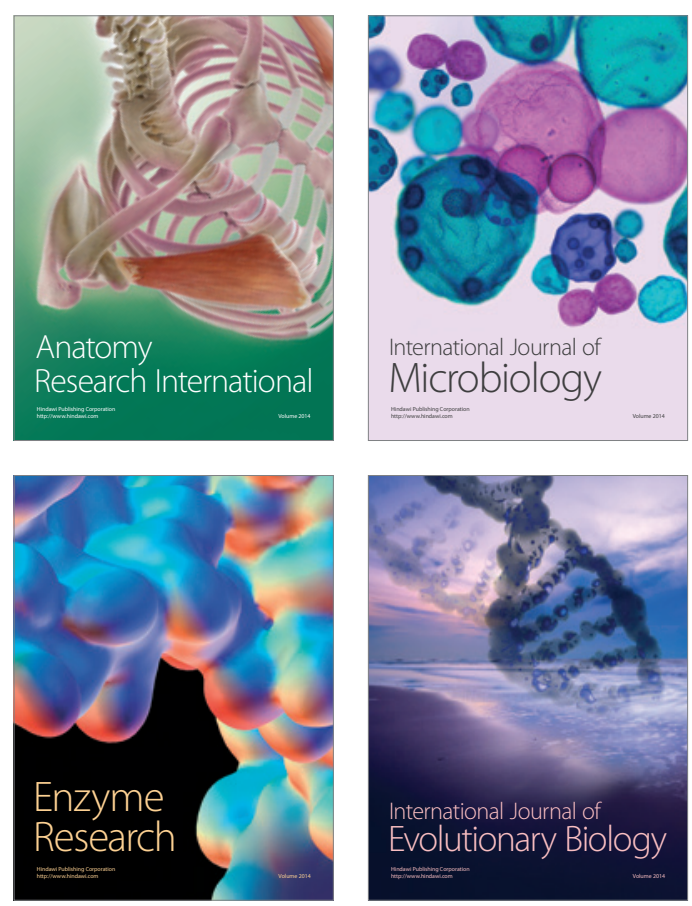
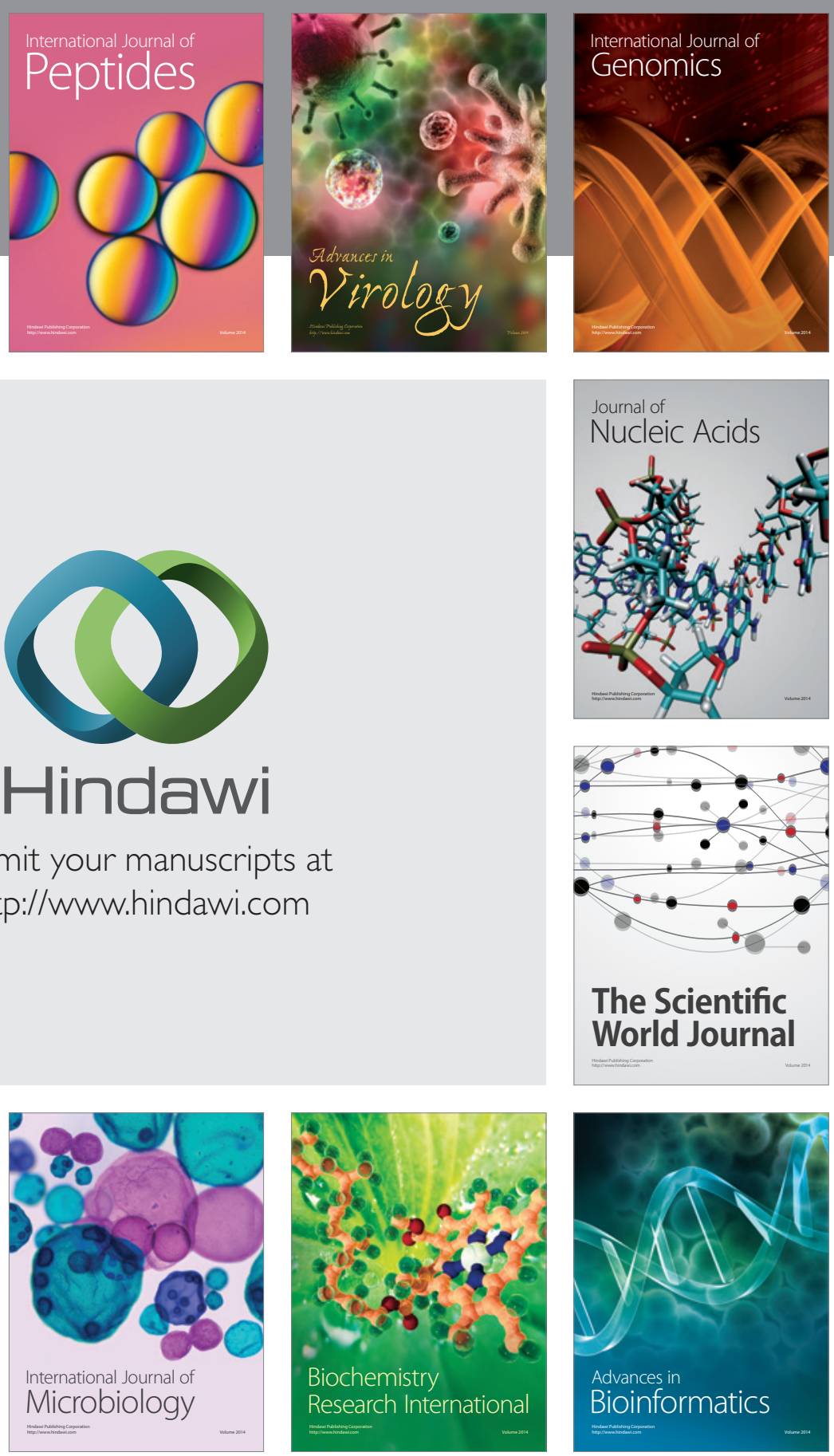

The Scientific World Journal
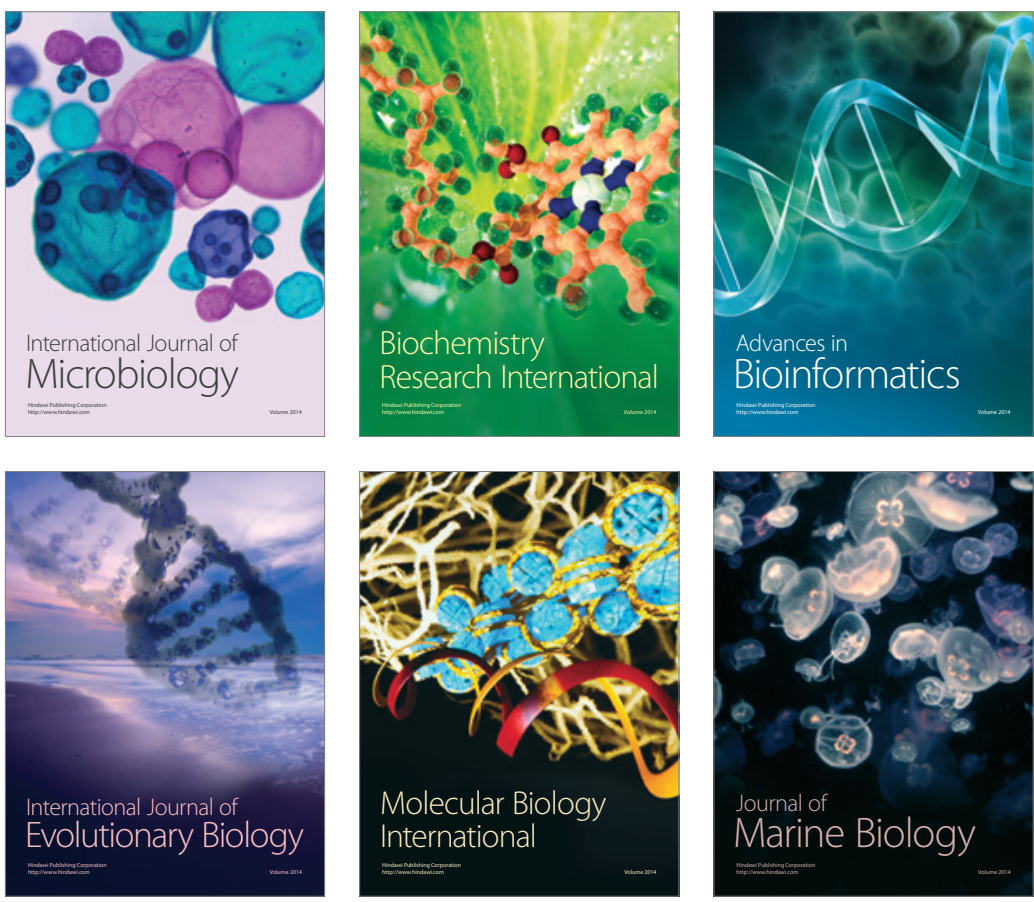